\title{
Antenatal depression and suicidal ideation among rural Bangladeshi women: a community-based study
}

\begin{abstract}
Depression during pregnancy is a significant public health problem because of its negative effects on the health of both mother and infant. Data on its prevalence and determinants are lacking in Bangladesh. To estimate the prevalence of depression during pregnancy and to identify potential contributory factors among rural Bangladeshi women, a community-based study was conducted during 2005 in Matlab sub-district, a rural area of eastern Bangladesh. Three hundred and sixty-one pregnant women were identified through an existing health and demographic surveillance system covering a population of 110,000 people. The women were interviewed at home at 34-35 weeks of pregnancy. Information on risk factors was collected through structured questionnaires, with the Bangla version of the Edinburgh Postnatal Depression Scale (EPDS-B) used to measure their psychological status. Both univariate analysis and multivariate logistic regression were applied using the SPSS 15.0 statistical software. The prevalence of depression at 34-35 weeks pregnancy was 33\% (95\% CI, 27.6 - 37.5). After adjustment in a multivariate logistic regression model, a history of being beaten by her husband either during or before the current pregnancy had the highest association with depression followed by having an unhelpful or unsupportive mother-in-law or husband, and family preference for a male child. Of the antenatally depressed women, 17 (14\%) admitted to thoughts of selfharm during the pregnancy. This paper further explores the reasons why women have considered some form of self-harm during pregnancy. Depression during pregnancy is common among Bangladeshi women, with about a third being affected. The study highlights the need to allocate resources and develop strategies to address depression in pregnancy.
\end{abstract}

Keywords: Antenatal depression, Self-harming thoughts, Suicide, Rural women, Bangladesh. 


\section{Introduction:}

Although pregnancy is often viewed as a period of emotional enlightenment, many women experience depression during this period. A systematic review of depressive symptoms worldwide reported a mean prevalence of depression of $12 \%$ (range 851\%) during the third trimester of pregnancy (Bennett et al. 2004). Women from socio-economically disadvantaged backgrounds appear to suffer from even higher rates of depression. A community-based study in south Asia found $25 \%$ of pregnant women suffering from depression (Rahman et al. 2003). Severe forms of depression, characterized by the idea of suicide or self-harming, are also relatively common in pregnancy. Indeed a recent review in this area reported that 5 to $14 \%$ of women had expressed the idea of suicide or self-harming thought during pregnancy and the postnatal period (Lindahl et al. 2005).

Compared to postnatal depression, depression during pregnancy has not received much attention in the health care community and in the popular press. This may be due to the greater focus usually directed towards the physical wellbeing of the pregnant mother, as opposed to her mental health. There may also be a general lack of awareness about the fact that two thirds of cases of postnatal depression actually start before the birth of the baby, usually during the third trimester of pregnancy (Chandran et al. 2002; Limlomwongse \& Liabsuetrakul, 2006; Patel et al. 2002; Rahman et al., 2003).

Depression during pregnancy can have serious health consequences on maternal and child health. Antenatal depression has been associated with low birth weight babies (Patel \& Prince, 2006; Rahman et al. 2007), premature delivery (Ferri et al. 2007), inadequate prenatal care (Kelly et al. 1999), pre-eclamsia (Kurki et al. 2000), alcohol and substance use (Harrison \& Sidebottom, 2008), poor nutrition and diarrhoea among infants (Rahman et al. 2004), postnatal depression itself and suicidal ideation (Freitas et al. 2008).

A number of socio-demographic risk factors have been identified for depression during pregnancy, including young age, lack of education, being unmarried and unemployed (Bolton et al. 1998; Faisal-Cury \& Rossi Menezes, 2007; Lovisi et al. 2005). Increased parity and lack of support, particularly poor support from partner/husband have also been associated with depression in both developed and developing countries (Bolton et al., 1998; Patel et al., 2002). In particular, physical abuse by intimate partners before or during pregnancy is one of the most important factors for antenatal depression (Lovisi et al., 2005; Martin et al. 2006). It is not unlikely that such physical abuse may contribute to a worsening of women's depression status, thus leading to terminal symptoms of suicidal ideation amongst abused women. Physical abuse by the husband has also been shown to increase the likelihood of suicidal ideation among women of reproductive age in Bangladesh by as much as four times (Naved \& Akhtar, 2008).

While there are few studies of actual suicidal mortality during pregnancy in developed countries (Appleby 1999), they are even rarer in developing countries (Appleby 1991). Of those undertaken in developing countries, an earlier study on maternal mortality in Matlab conducted in the late 1980s found that suicide was the second most frequent cause of death, accounting for $20 \%$ of all deaths during the antenatal 
period (Fauveau \& Blanchet, 1989). Though psychological status was not reported for those pregnant women, it can be speculated that some of them would have been depressed, a conclusion supported by a recent Canadian study that found $40 \%$ of pregnant women hospitalized for psychosis (an extreme form of depression) had thought about suicide (Bowen \& Muhajarine, 2006).

This paper reports the results of a study on the prevalence and associated contributory factors of antenatal depression among Bangladeshi pregnant women who also held self-harming thoughts or suicidal ideation.

\section{Methods}

The study was carried out in Matlab, a rural sub-district 55kms southwest of Dhaka, the capital of Bangladesh. Matlab is flooded for part of the year, and people mostly use boats or walking for transportation. The main source of income is agriculture or fishing for Matlab people. As in other rural areas of Bangladesh, the majority of women are involved in household work and childcare. A health and demographic surveillance system maintained by the International Centre for Diarrhoeal Disease Research, Bangladesh (ICDDR,B) covers about a third of Matlab district. In the half of the surveillance area covering 110,000 population, services are provided through primary health care clinics to reproductive age women and their children under five years of age. All residents in the surveillance area are assigned a unique identification number. The unique individual identification number and the longitudinal data collection system of Matlab made it possible to identify pregnant women at the community level, an important feature for selection of subjects for this study.

\section{Study design}

A cohort of women were followed up from pregnancy to the postpartum period in an epidemiological investigation of postnatal depression in Bangladesh. Details of the study samples have been described elsewhere (Gausia et al. 2008). In brief, from a list of 410 pregnant women, a total of 361 women were recruited during pregnancy. This paper explores the prevalence of antenatal depression and associated contributory factors in the original sample of 361 women, as well as women's understanding of self-harming ideation which was extracted from item 10 of the Bangla version of the Edinburgh Postnatal Depression Scale (EPDS-B) in current pregnancy and through open ended description (Gausia et al. 2007). Women who endorsed this particular item of the EPDS-B scale were asked to elaborate further about their response. Respondents were interviewed for further details if they answered in the affirmative to item 10 of the EPDS-B instrument, which states 'The thought of harming myself has occurred to me -' and has the following responses: Yes, quite often=3, Sometimes=2, Hardly ever $=1$ and Never $=0$ (Cox et al. 1987). Extra care was taken regarding the self-harming item of the EPDS-B due to reports of over-rating and misinterpretation of this item of the EPDS scale among women in another study (Green et al. 1999). The validation study on EPDS-B against standard diagnosis of depression among Bangladeshi women showed a sensitivity of $89 \%$ and a specificity of $87 \%$ at cut-off scores of 10 (Gausia et al. 2007).

\section{Data collection}

Data were collected during a 6-month period from July-December 2005. Eight female field workers were trained for the project to administer the study questionnaires on 
selected study participants at 34-35 weeks of pregnancy at their home. In some instances interviews were delayed for up to a week as some participants were not available on the scheduled date of interview. The first part of the study questionnaire was designed to collect information on the woman's current pregnancy, on whether it was wanted or unwanted, preferences for gender of the unborn child, family structure, help received from family members, relationship with family members (particularly the woman's relationship with her mother-in-law), husband's support, whether she had been physically abused by her husband, and past and family history of mental health. The EPDS-B was then administered to assess psychological well-being. Finally, the detail descriptive interview was undertaken with women if they answered in the affirmative to item 10 of the EPDS-B instrument.

\section{Data analysis}

The data were coded and analyzed using the SPSS-15 statistical package. An independent-samples t-test was undertaken to examine differences in the mean EPDSB scores of depressed and non-depressed participants. The EPDS-B cutoff score of 10 was used to categorize participants as depressed (scores 10 or above) or nondepressed (scores $<10$ ). Both univariate and logistic regression analyses were also carried out to examine significant factors associated with antenatal depression. Variables that were found significant in the univariate analyses were entered in forward logistic regression analyses. All women with total EPDS-B scores of 10 or above were advised to contact the district level hospital for adequate follow up. Women's description about the idea of self-harming thoughts were analysed based on a thematic content analysis.

\section{Results}

\section{Sample characteristics}

The ages of the 361 study participants ranged from 17 to 41 years, with a mean age of 26.8 years $(S D=5.8$ years). Ninety five percent were interviewed at 33-36 weeks of pregnancy. The majority (88\%) of the study participants were Muslim while the remaining were Hindus. One-fifth (20\%) of the study participants were illiterate and had never been to school and one-quarter (25\%) had an education of between 1 and 5 years. Very few (5\%) participants had education beyond 10 years of schooling. All were married except for one who had been widowed while pregnant. The great majority (96\%) were housewives and living in a nuclear family (57\%) with their husband and children. Almost a third (32\%) of the participants did not have any children. Among those who had children, 48\% had one child, 33\% had two children and the remaining $19 \%$ had three and more children with a maximum of 5 .

In the majority of cases (71\%), the pregnancy was stated to have been planned while in the remaining (29\%), the current pregnancy was unwanted. Only a fifth (21\%) wished to give birth to a daughter compared to $43 \%$ who expressed a desire to give birth to a son. The remaining 35\% mentioned that they would welcome the baby irrespective of the gender of the new born.

Almost a third, 31\% ( $n=112)$, of the women reported being physically abused by their husband, including $6 \%(n=22)$ who were abused during the current pregnancy. Among the women reporting being beaten by their husband, 15 were physically abused by their husband repeatedly during this pregnancy and before. These 22 
abused women in current pregnancy were considered in a further analysis of antenatal depression.

The majority (88\%) of study participants had a mother-in-law who was still living. A little less than half (45\%) of the study participants mentioned that their relationship with their mother-in-law was 'very bad' to 'average'. Thirteen (4\%) admitted to being physically abused by their mother-in-law including two who were abused during the current pregnancy.

Of 361 participants, 119 had total EPDS-B scores of 10 or above, indicating a point prevalence of depression during pregnancy of 33\% (95\% CI: 27.6 - 37.5\%). Figure 1 shows the distribution of total EPDS-B scores among study participants. The mean EPDS-B scores for non-depressed and depressed participants were 4.4 (SD 2.8) and 13.4 (SD 3.6) respectively. The differences in the mean scores for depressed and nondepressed participants were statistically significant $(\mathrm{t}=-26.4$, $\mathrm{df}=359, \mathrm{p}<0.001)$.

\section{Figure 1 will be here}

A number of independent potential risk factors for antenatal depression were examined (table 1). Study participants with no education or an education level up to year 5 were 1.4 times at higher risk of developing depression than participants with more than 5 years of schooling. Participants reporting a poor relationship with their mother-in-law or having an unhelpful/unsupportive mother-in-law were twice more likely to have depression than those reporting being on good terms with their motherin-law.

\section{Table 1 will be here}

Unwanted pregnancies were significantly associated with an increased risk of depression. Similarly, women who preferred a male baby were 1.4 times at higher risk for depression than those who did not have any particular gender preference for their child. Study participants were two to three times at higher risk of depression if their husbands were unhelpful and/or physically abusive during pregnancy.

\section{Table 2 will be here}

After adjustment in the multivariate logistic model (table 2), depression in pregnancy was independently associated with: women wanting a son, receiving no help from her mother-in-law, receiving no help from her husband, and being beaten by her husband during the current pregnancy and before. Of these, being beaten by the husband both during the current pregnancy and before had the highest contribution for depression. The gender of the unborn child was also found to be a significant stress factor for study participants. Indeed, women wishing to give birth to a son were independently associated with the risk of having antenatal depression. 
Why do pregnant women want to die?

Nineteen study participants obtained scores of 1 to 3 on item 10 of the EPDS-B scale indicating that the idea of self harming thoughts had occurred to them during the pregnancy. Of these 19 participants, 17 had a total EPDS score of 10 or more, indicating possible clinical depression. These 19 participants were asked to elaborate further about their response to item 10. Their open-ended description confirmed that they had understood the self-harming item clearly. Repeated reading of the women's description about self-harming thoughts identified a number of concepts which are discussed in the following section.

In the current study, thoughts of self-harm or suicide among women appeared to derive from problems with family members, particularly their husbands, and from financial hardship. Physical and psychological abuse by her husband was the most cited cause of thoughts of self-harm in these women.

Physical abuse by the husband

Study participants mentioned that they were beaten by their husband for no good reason and sometimes beaten severely and repeatedly. Although we have no information regarding the educational level of these husbands and their job skills, most would be expected to have limited education and possibly have no specific job skills beyond farming or fishing because of the rural and social environment of Matlab. The parental homes of the women also generally were not welcoming or supportive in the event of spousal violence, due to the shame or stigma attached to such disclosure. If the woman went back to her parents' home to escape spousal violence, it was perceived to bring a "bad name" for the family, making it difficult for the family to organize the marriage of any of her unmarried younger siblings. A newly married young participant described

My husband threw puta (pestle made of stone) on to my tummy; and he used to beat me almost everyday. Also I do not have much happiness in my parent's house - so I wish to die. I have three more sisters waiting to get married in my parent's house. [Age 18, had no children before the current pregnancy].

Another middle aged study participant who had three children mentioned that

My husband always quarrels with me. He used to beat me for no good reason. He does not work regularly. [Age 36, had three children].

In addition to being physically abused by their husbands, many women also experienced harassment and physical abuse by her husband's family members. A 23 year old woman described that

My husband beats me hard. I am extremely upset by his repeated abuse. My husband's elder sister and his younger sister also beat me. Often, I think of wanting to die because of all this beating [Age 23, had one child].

\section{Commitment of dowry in wedding}

The practice of dowry, where the bride's family commits to give gifts and money to the groom, while officially outlawed, is common-practice and often leads to many 
cases of wife beating in Bangladesh if the woman's family is unable to fulfill its commitment. A 19 year old respondent describes

There was a commitment in my wedding (dowry) to send my husband 'bidesh' (abroad) for employment. But delays in sending him 'bidesh' has led to regular quarrels with him, and I now often contemplate suicide [Age 19, had no children].

Even if a women's parents and other family member give a substantial amount of money to the bridegroom to partially fulfill the requirement of dowry, it does not mean that the marriage will be happy and non-abusive and does not help in drawing attention, cooperation and kindness from her husband. A twenty-four year old mother of one child described that

There was a commitment in my wedding (dowry) that my brothers would send my husband to 'bidesh' (foreign country). Later, instead of sending him 'bidesh' (outside the country), one lac taka (AU\$ 2000) was given to him to run a business. He took the money (seventy thousand taka) with him and left home to do a business in Sylhet district. Since he left five months ago, he has not contacted me. [Age 24, had one child].

Other study participants also mentioned lack of care, attention and supports from their husband as described in the above citation.

\section{Have female children}

The gender of the unborn child was another concern for many mothers. Mothers who had given birth to a daughter in a previous pregnancy often faced recriminations from her husband and his family members for not bearing a male child. For instance, a 28 year old mother of two daughters voiced her intention to take her life if she gave birth to another girl child. Husbands sometimes threatened their wives with marrying another woman if they fail to give birth to a son.

It is thus not surprising that Bangladeshi rural women, often illiterate and discouraged by social norms to seek employment outside the home, would become depressed by their situation in life, especially when abused physically and mentally by their husband and his family. When asked about how they would take their lives, almost all replied that they would ingest poison, commonly agricultural pesticides. One replied she would put herself in the way of an oncoming truck.

\section{Discussion}

The study demonstrated the high prevalence of antenatal depression among rural Bangladeshi women. One third of women were found to be depressed during their third trimester of pregnancy. Socio-cultural factors and physical violence were found to be associated with this antenatal depression. Indeed, after adjustment in a multivariate logistic model, a women being beaten by her husband had the highest association to depression followed by an unhelpful or unsupportive mother-in-law, unhelpful/unsupportive husband, and preference for a male child. Of the antenatally depressed women, $14 \%$ admitted to thoughts of self-harm during their current pregnancy. 
The point prevalence of antenatal depression was 33\% in this study, which is higher than the $12 \%$ prevalence reported in a systematic review of studies undertaken in developed countries in all but one instance (Bennett et al., 2004). Therefore, lower prevalence of antenatal depression in this systematic review may not be generalisable to developing countries. Despite this, however, there appears to be some consistency in prevalence rates across studies in various countries which have used the EPDS. For example, the prevalence of antenatal depression was 29\% in London (Bolton et al., 1998), 39\% in Brazil (Da-Silva et al. 1998) and 27\% in Canada (Bowen \& Muhajarine, 2006). A Pakistani study found 25\% prevalence of antenatal depression on clinical assessment in neuropsychiatry (SCAN) interview (Rahman et al. 2003).

The underlying mechanisms or aetiology of antenatal depression are still not clearly understood. It has been hypothesized that hormonal changes related to pregnancy and delivery and the function of the brain may be associated with depression during this period (Kammerer et al. 2006). A recent review suggested that changes in the function of the hypothalamic-pituitary adrenal (HPA) axis and the raised level of cortisol hormone may be associated with antenatal depression (Kammerer et al. 2006). Concerns about the impending birth, such as labour, outcome of delivery, and health of the unborn child may make pregnant women more vulnerable to anxiety and depression, and could contribute to the higher prevalence of depression during the antenatal period compared to the postpartum period (Heron et al. 2004).

Almost a third (31\%) of the women in this study reported being physically abused by their husband, including 6\% who were abused during the current pregnancy. Consistent with other studies conducted in both developed and developing countries, this study also confirmed that physical abuse by a women's husband during pregnancy was an independent risk factor for antenatal depression (Lovisi et al. 2005; Rodriguez et al. 2008).

Explanations for this appear to be rooted in the culture of many traditional Asian societies. In these cultures the newly wed couple usually becomes part of the husband's extended or joint family of his parents and siblings. Rarely do couples set up home on their own. In Matlab, this tradition too is the norm. In such cases, the wife's mother-in-law is the matriarch who holds effective power and control over household matters. The daughter-in-law is under her strict guidance and supervision, and is expected to carry out all her instructions and household chores. In this study, $96 \%$ of women were housewives and a substantial proportion (43\%) of these women lived in a joint family. Even if the mother-in-law did not live with the family, in-laws often instigate violence or abuse (Naved \& Persson, 2005). During pregnancy, such conflicts are likely to increase if the daughter-in-law fails to discharge her household duties owing to her physical weakness or illness. As this was a cross-sectional study, we cannot confirm the reported poor relationships with their mother in-laws and depression status in women.

While any form of abuse should not be tolerated, spousal abuse has been tolerated in some societies including Bangladesh with abuse in a marital relationship not seen as important. Among the very few published studies examining abuse in Bangladesh, a recent survey found that the majority of Bangladeshi men felt that a wife was accountable to her husband for her behaviour and that abuse (violence) was an 
acceptable form of corrective punishment (UNFPA, 2003). Although a third of the respondents in the survey expressed views against abuse in general, they were not against marital abuse.

Self-harming thoughts are more common than the actual act of self-harm such as suicide, attempted suicide and self inflicted injury, as was observed in our study. This finding is consistent with studies in Asia and elsewhere (Chan et al. 2002; ChewGraham et al. 2002; Lindahl et al. 2005; Naved \& Akhtar, 2008). A recent study on wife abuse and suicidal ideation in Bangladesh documented that 5- 6\% of women had contemplated suicide in the last 4 weeks before the survey with a four-fold increase in such ideas among those who had experienced severe physical violence by their husband (Naved \& Akhtar, 2008). A qualitative study on South Asian women also reported that self-harm was seen as a coping strategy to deal with a women's distress (Chew-Graham et al. 2002). In the current study, thoughts of self-harm or suicide among women appeared to derive from problems with family members, particularly physical violence by husbands, and from financial hardship both in their family and that of the woman's parents. Preference for a male child also contributed to selfharming thoughts.

In a patriarchal society such as Bangladesh women are often blamed for giving birth to a female baby with husbands holding women responsible for the gender of their children (Imam, 2003). This is common in the community irrespective of social class, education levels and levels of awareness of scientific explanations regarding how the sex of the unborn child is determined. Preference for a male baby is apparent across a number of countries. For example, a recent survey on pregnant women in Egypt documented that due to social reasons (help in household work, lower risk of divorce and old age care/support) and psychological reasons (siblings were girls) most women preferred to give birth to a son (El-Gilany \& Shady, 2007). Thus, it can be assumed that pregnant women in this study who wished to give birth to a boy baby would be significantly more depressed than those women who did not have such a wish.

\section{Conclusions and policy implications}

Given the disturbingly high levels of antenatal depression and suicidal ideation found in this study, and its association with physical abuse by the husband and/or his family, there is an urgent and critical need to raise awareness of the issue in the wider community. While government legislation exists for the protection of women against abuse in Bangladesh, there needs to be far greater enforcement of such laws, coupled with extensive programs to raise public awareness of the problem. Behavioural change interventions could be developed and implemented. Further applied research should be encouraged to explore how Bangladeshi women at risk of spousal abuse can be protected, and how such abuse can be prevented in the first place.

\section{References}

Appleby, L. (1991). Suicide during pregnancy and in the first postnatal year. Bmj, 302(6769), 137-140.

Bennett, H. A., Einarson, A., Taddio, A., Koren, G., \& Einarson, T. R. (2004). Prevalence of depression during pregnancy: systematic review. Obstet Gynecol, 103(4), 698-709. 
Bolton, H. L., Hughes, P. M., Turton, P., \& Sedgwick, P. (1998). Incidence and demographic correlates of depressive symptoms during pregnancy in an inner London population. J Psychosom Obstet Gynaecol, 19(4), 202-209.

Bowen, A., \& Muhajarine, N. (2006). Prevalence of antenatal depression in women enrolled in an outreach program in Canada. J Obstet Gynecol Neonatal Nurs, 35(4), 491-498.

Chan, S. W., Levy, V., Chung, T. K., \& Lee, D. (2002). A qualitative study of the experiences of a group of Hong Kong Chinese women diagnosed with postnatal depression. J Adv Nurs, 39(6), 571-579.

Chandran, M., Tharyan, P., Muliyil, J., \& Abraham, S. (2002). Post-partum depression in a cohort of women from a rural area of Tamil Nadu, India. Incidence and risk factors. Br J Psychiatry, 181, 499-504.

Chew-Graham, C., Bashir, C., Chantler, K., Burman, E., \& Batsleer, J. (2002). South Asian women, psychological distress and self-harm: lessons for primary care trust. Health and social care in the community, 10(5), 339-347.

Cox, J. L., Holden, J. M., \& Sagovsky, R. (1987). Detection of postnatal depression. Development of the 10-item Edinburgh Postnatal Depression Scale. $\mathrm{Br} J$ Psychiatry, 150, 782-786.

Da-Silva, V. A., Moraes-Santos, A. R., Carvalho, M. S., Martins, M. L., \& Teixeira, N. A. (1998). Prenatal and postnatal depression among low income Brazilian women. Braz J Med Biol Res, 31(6), 799-804.

El-Gilany, A. H., \& Shady, E. (2007). Determinants and causes of son preference among women delivering in Mansoura, Egypt. East Mediterr Health J, 13(1), 119-128.

Faisal-Cury, A., \& Rossi Menezes, P. (2007). Prevalence of anxiety and depression during pregnancy in a private setting sample. Arch Womens Ment Health, 10(1), 25-32.

Fauveau, V., \& Blanchet, T. (1989). Deaths from injuries and induced abortion among rural Bangladeshi women. Soc Sci Med, 29(9), 1121-1127.

Ferri, C. P., Mitsuhiro, S. S., Barros, M. C., Chalem, E., Guinsburg, R., Patel, V., et al. (2007). The impact of maternal experience of violence and common mental disorders on neonatal outcomes: a survey of adolescent mothers in Sao Paulo, Brazil. BMC Public Health, 7, 209.

Freitas, G. V., Cais, C. F., Stefanello, S., \& Botega, N. J. (2008). Psychosocial conditions and suicidal behavior in pregnant teenagers : A case-control study in Brazil. Eur Child Adolesc Psychiatry, 17(6), 336-342.

Gausia, K., Fisher, C., Algin, S., \& Oosthuizen, J. (2007). Validation of the Bangla version of the Edinburgh Postnatal Depression Scale for a Bangladeshi sample. Journal of Reproductive and Infant Psychology, 25(4), 308.

Gausia, K., Fisher, C., Ali, M., \& Oosthuizen, J. (2008). Magnitude and contributory factors of postnatal depression: a community-based cohort study from a rural subdistrict of Bangladesh. Psychol Med, 1-9.

Gausia, K., Hamadani, J. D., Islam, M. M., Ali, M., Algin, S., Yunus, M., et al. (2007). Bangla translation, adaptation and piloting of Edinburgh Postnatal Depression Scale. Bangladesh Med Res Counc Bull, 33(3), 81-87.

Green, J. M., Snowdon, C., \& Statham, H. (1999). EPDS by post. Br. J. Psychiatry, 158, 865.

Harrison, P. A., \& Sidebottom, A. C. (2008). Alcohol and Drug Use Before and During Pregnancy: An Examination of Use Patterns and Predictors of Cessation. Matern Child Health J. 
Heron, J., O'Connor, T. G., Evans, J., Golding, J., \& Glover, V. (2004). The course of anxiety and depression through pregnancy and the postpartum in a community sample. J Affect Disord, 80(1), 65-73.

Imam, M. J. (2003). Women's right in Bangladesh: The need for a paradigm shift. The Daily Star. Dhaka: The Daily Star Internet edition, retrieved on 18.3.2009. http://www.thedailystar.net/law/200309/04/monitor.htm.

Kammerer, M., Taylor, A., \& Glover, V. (2006). The HPA axis and perinatal depression: a hypothesis. Arch Womens Ment Health, 9(4), 187-196.

Kelly, R. H., Danielsen, B. H., Golding, J. M., Anders, T. F., Gilbert, W. M., \& Zatzick, D. F. (1999). Adequacy of prenatal care among women with psychiatric diagnoses giving birth in California in 1994 and 1995. Psychiatr Serv, 50(12), 1584-1590.

Kurki, T., Hiilesmaa, V., Raitasalo, R., Mattila, H., \& Ylikorkala, O. (2000). Depression and anxiety in early pregnancy and risk for preeclampsia. Obstet Gynecol, 95(4), 487-490.

Limlomwongse, N., \& Liabsuetrakul, T. (2006). Cohort study of depressive moods in Thai women during late pregnancy and 6-8 weeks of postpartum using the Edinburgh Postnatal Depression Scale (EPDS). Arch Womens Ment Health, 9(3), 131-138.

Lindahl, V., Pearson, J. L., \& Colpe, L. (2005). Prevalence of suicidality during pregnancy and the postpartum. Arch Womens Ment Health, 8(2), 77-87.

Lovisi, G. M., Lopez, J. R., Coutinho, E. S., \& Patel, V. (2005). Poverty, violence and depression during pregnancy: a survey of mothers attending a public hospital in Brazil. Psychol Med, 35(10), 1485-1492.

Martin, S. L., Li, Y., Casanueva, C., Harris-Britt, A., Kupper, L. L., \& Cloutier, S. (2006). Intimate partner violence and women's depression before and during pregnancy. Violence Against Women, 12(3), 221-239.

Naved, R. T., \& Akhtar, N. (2008). Spousal violence against women and suicidal ideation in bangladesh. Womens Health Issues, 18(6), 442-452.

Naved, R. T., \& Persson, L. A. (2005). Factors associated with spousal physical violence against women in Bangladesh. Stud Fam Plann, 36(4), 289-300.

Patel, V., \& Prince, M. (2006). Maternal psychological morbidity and low birth weight in India. Br J Psychiatry, 188, 284-285.

Patel, V., Rodrigues, M., \& DeSouza, N. (2002). Gender, poverty, and postnatal depression: a study of mothers in Goa, India. Am J Psychiatry, 159(1), 43-47.

Rahman, A., Bunn, J., Lovel, H., \& Creed, F. (2007). Association between antenatal depression and low birthweight in a developing country. Acta Psychiatr Scand, 115(6), 481-486.

Rahman, A., Iqbal, Z., Bunn, J., Lovel, H., \& Harrington, R. (2004). Impact of maternal depression on infant nutritional status and illness: a cohort study. Arch Gen Psychiatry, 61(9), 946-952.

Rahman, A., Iqbal, Z., \& Harrington, R. (2003). Life events, social support and depression in childbirth: perspectives from a rural community in the developing world. Psychol Med, 33(7), 1161-1167.

Rodriguez, M. A., Heilemann, M. V., Fielder, E., Ang, A., Nevarez, F., \& Mangione, C. M. (2008). Intimate partner violence, depression, and PTSD among pregnant Latina women. Ann Fam Med, 6(1), 44-52.

UNFPA. (2003). Male attitudes towards violence against women in Bangladesh. Dhaka: UNFPA. 